\title{
Immune Reactivity and Pseudoprogression or Tumor Flare in a Serially Biopsied Neuroendocrine Patient Treated with the Epigenetic Agent RRx-001
}

\author{
Corey A. Carter ${ }^{a} \quad$ Bruno Schmitz $^{\mathrm{a}} \quad$ P. Gabriel Peterson ${ }^{\mathrm{a}} \quad$ Mary Quinn $^{\mathrm{a}}$ \\ Aiste Degesys $^{a} \quad$ John Jenkins $^{a} \quad$ Bryan Oronsky $^{b}$ Jan Scicinski ${ }^{b}$ \\ Scott Caroen ${ }^{b}$ Tony R. Reid ${ }^{c} \quad$ Pedro Cabrales $^{d} \quad$ Christina Brzezniak $^{a}$ \\ ${ }^{a}$ Walter Reed National Military Medical Center, Bethesda, Md., ${ }^{b}$ EpicentRx, Inc., \\ Mountain View, Calif., and ${ }^{C}$ Moores Cancer Center, and ${ }^{d}$ Department of Bioengineering, \\ University of California San Diego, La Jolla, Calif., USA
}

\section{Key Words}

Neuroendocrine tumor - Immune reactivity · Pseudoprogression - Tumor flare · Serial biopsy . RRx-001

\begin{abstract}
Neuroendocrine tumors (NETs) are grouped together as a single class on the basis of histologic appearance, immunoreactivity for the neuroendocrine markers chromogranin A and synaptophysin, and potential secretion of hormones, neurotransmitters, neuromodulators and neuropeptides. Nevertheless, despite these common characteristics, NETs differ widely in terms of their natural histories: high-grade NETs are clinically aggressive and, like small cell lung cancer, which they most closely resemble, tend to respond to cisplatin and etoposide. In contrast, low-grade NETs, which as a rule progress and behave indolently, do not. In either case, the treatment strategy, apart from potentially curative surgical resection, is very poorly defined. This report describes the case of a 28 -year-old white male with a diagnosis of highgrade NET of undetermined primary site metastatic to the lymph nodes, skin and paraspinal soft tissues, treated with the experimental anticancer agent RRx-001, in the context of a phase II clinical trial called TRIPLE THREAT (NCT02489903); serial sampling of tumor material through repeat biopsies demonstrated an intratumoral inflammatory response, including the amplification of infiltrating $T$ cells, which correlated with clinical and symptomatic benefit.
\end{abstract}

\section{KARGER}


Carter et al.: Immune Reactivity and Pseudoprogression or Tumor Flare in a Serially Biopsied Neuroendocrine Patient Treated with the Epigenetic Agent RRx-001

This case suggests that pseudoprogression or RRx-001-induced enlargement of tumor lesions, which has been previously described for several RRx-001-treated patients, is the result of tumoral lymphocyte infiltration.

2016 The Author(s)

Published by S. Karger AG, Basel

\section{Introduction}

Neuroendocrine tumors (NETs) are rare neoplasms (incidence of 2.48-5.86 per 100,000 per year [1] with an estimated prevalence of $\sim 105,000$ patients in the United States, making it an orphan disease [2]). Despite a similar histology and immunoreactivity for the neuroendocrine markers chromogranin A and synaptophysin [3], differences in terms of anatomic site of origin (see fig. 1) and clinical behavior characterize this heterogeneous disease.

Within the spectrum of NETs, on the one hand, are low-grade (G1 or G2) NETs (formerly termed carcinoid tumors), which usually follow an indolent clinical course, with a median overall survival typically measured in multiple years, and, on the other, are aggressive highgrade (G3) NETs with a propensity to metastasize and a median overall survival typically measured in months [4]. The management of NETs with systemic therapies is controversial but the current consensus recommends somatostatin analogues for low- to intermediategrade NETs, especially carcinoid tumors [5], and platinum-based doublets for high-grade NETs [6] when metastatic lesions are present; effective later-line chemotherapy is uncertain.

RRx-001 is a hypoxia-selective, systemically nontoxic, pan-epigenetic anticancer agent [7-9] with immunostimulatory properties [10] that has previously demonstrated activity in NETs [11]; it is currently under investigation in multiple clinical trials, including in combination with the PD-1 checkpoint inhibitor nivolumab (NCT02518958). The hypothesized mechanism of RRx-001-induced pseudoprogressive enlargement of tumor lesions, which has been previously observed and reported in several RRx-001-treated patients [7, 12], including a previous patient with high-grade neuroendocrine disease [11], is immune infiltration.

Here, we present the case of a male 28-year-old patient at Walter Reed National Military Medical Center with a diagnosis of high-grade NET of undetermined primary site, refractory to cisplatin and etoposide, who is currently receiving treatment with RRx-001 in the context of an open-label clinical trial called TRIPLE THREAT (NCT02489903). Per the TRIPLE THREAT protocol, patients with small cell lung cancer, non-small cell lung cancer and highgrade NETs (hence the name TRIPLE THREAT) receive once weekly $4 \mathrm{mg}$ RRx-001 coinfused with autologous blood until progression, followed by re-challenge with the same platinum regimen used in first line. This design is intended to investigate the potential of RRx-001 to episensitize tumors [13], or, in other words, to epigenetically resensitize them to previously effective therapies. Of note, in a role reversal of sorts between the passively compliant patient and actively treating physician, the patient, who is fully engaged in making decisions about his care, has unusually insisted on serial multiple-site biopsies during treatment with RRx-001.

\section{Case Report}

A 28-year-old male veteran with a histologically well-differentiated NET of unknown primary that has been classified as high grade due to a Ki-67 proliferation index $>20 \%$ previously received 6 cycles of cisplatin/carboplatin as first-line chemotherapy, to which he initially responded until aggressive progression was detected on CT scan. At this point, the 
Carter et al.: Immune Reactivity and Pseudoprogression or Tumor Flare in a Serially Biopsied Neuroendocrine Patient Treated with the Epigenetic Agent RRx-001

patient was enrolled on the clinical trial TRIPLE THREAT (NCT02489903) for experimental treatment with RRx-001. Approximately 6 weeks after starting RRx-001, the patient presented with sudden growth acceleration of a pathologic 'non-target' cervical lymph node in the context of a dramatic symptomatic improvement in terms of appetite and energy levels. The 'growth' on CT scan (fig. 2) was significant enough $(3.05-3.33 \mathrm{~cm}$ ) to discontinue RRx001.

However, because the sudden nodal enlargement was so at odds with the dramatic clinical improvement, his physician (C.A.C.) opted for a core needle biopsy on the suspicion of tumor flare or pseudoprogression. At the insistence of the patient, core needle biopsy was also obtained on a retroperitoneal lymph node. Pathologist-read hematoxylin and eosinstained histological sections from these core needle biopsies at 6 weeks demonstrated significantly decreased cellularity and the accumulation of T cells visualized with anti-CD3 antibodies. By 12 weeks, repeat biopsies indicated increased $\mathrm{T}$ cell infiltrate as demonstrated on the graphs below (fig. 3). The percentage of histologically intact tumor and the percentage of necrotic tumor were scored per slide.

Consistent with the entity of pseudoprogression or reactive tumor enlargement, repeat imaging at 4 months (fig. 4) demonstrated lymph node shrinkage from 3.33 to $3.14 \mathrm{~cm}$, correlating with the decreased cellularity observed on core needle biopsy specimens.

\section{Discussion}

Owing to the rarity and heterogeneity of NETs as well as a dearth of randomized clinical trials, treatment guidelines, apart from radical curative surgery, are not well established, making it a challenging disease to manage. High-grade NETs have been called 'extrapulmonary small cell lung cancer' given their histologic similarity [14], leading to treatment with etoposide and cisplatin, one of the standard regimens for small cell lung cancer. However, the use of this regimen is limited by associated toxicities as well as the almost inevitable development of acquired drug and cross drug resistance. VEGF (e.g., sunitinib, sorafenib and bevacizumab) and mTOR (e.g., temsirolimus and everolimus) inhibitors have also been investigated with some evidence of success in the setting of low- to intermediate-grade NETs, e.g., carcinoid [15], but their feasibility in high-grade tumors has not been established.

Unlike these cytotoxic or molecularly targeted agents, the epigenetic inhibitor RRx-001 is not associated with any systemic hematological or nonhematological toxicities [7], which potentially makes it a very attractive option in a hard-to-treat tumor type like NET, where meaningful advances have been few and far between. The data from this highly motivated and multiply biopsied patient demonstrates evidence of immune reactivity in the form of $\mathrm{T}$ cell infiltration. The outcome of this lymphocytic infiltrate was tumor flare or so-called pseudoprogression - i.e., disease progression followed by regression - on repeat CT scans, similar to the transient enlargement of existing lesions seen with the CTLA-4 inhibitor ipilumumab [16]. This apparent tumor growth suggests the potential to misidentify early imaging of RRx-001 with traditional RECIST criteria as progression, inappropriately resulting in early discontinuation of a potentially effective therapy. The RRx-001-mediated increase in tumor-infiltrating lymphocytes also suggests a potential synergy with immunotherapies such as vaccines, oncolytic viruses, immune checkpoint blockers and costimulatory receptor agonists.

Enrollment in the TRIPLE THREAT trial is ongoing, and histological evaluation of biopsies from other patients that provide further evidence of RRx-001-mediated immune involvement will be reported. 
Carter et al.: Immune Reactivity and Pseudoprogression or Tumor Flare in a Serially Biopsied Neuroendocrine Patient Treated with the Epigenetic Agent RRx-001

\section{Statement of Ethics}

The patient described in this case report has given his informed consent as part of the TRIPLE THREAT clinical study (NCT02489903). This study protocol has been approved by the Walter Reed National Military Medical Center Institutional Review Board.

\section{Disclosure Statement}

B.O., J.S. and S.C. are employees of EpicentRx, Inc. EpicentRx, Inc. provided funding for the study. The remaining authors declare that they have no competing interests.

\section{References}

1 Hallet J, Law CH, Cukier M, Saskin R, Liu N, Singh S: Exploring the rising incidence of neuroendocrine tumors: a population-based analysis of epidemiology, metastatic presentation, and outcomes. Cancer 2015;121:589-597.

2 Yao JC, Hassan M, Phan A, Dagohoy C, Leary C, Mares JE, Abdalla EK, Fleming JB, Vauthey JN, Rashid A, et al: One hundred years after 'carcinoid': epidemiology of and prognostic factors for neuroendocrine tumors in 35,825 cases in the United States. J Clin Oncol 2008;26:3063-3072.

-3 Oberg K, Knigge U, Kwekkeboom D, Perren A; ESMO Guidelines Working Group: Neuroendocrine gastroentero-pancreatic tumors: ESMO Clinical Practice Guidelines for diagnosis, treatment and follow-up. Ann Oncol 2012;23(suppl 7):vii124-vii130.

4 Cooney K, Hayes T, Pritchett Mims M, Todd R, Worden F: Tumor Board Review: Guideline and Case Reviews in Oncology, ed 2. New York, Demos Medical Publishing, 2015.

5 Modlin IM, Lye KD, Kidd M: A 5-decade analysis of 13,715 carcinoid tumors. Cancer 2003;97:934-959.

6 Fjallskog ML, Granberg DP, Welin SL, Eriksson C, Oberg KE, Janson ET, Eriksson BK: Treatment with cisplatin and etoposide in patients with neuroendocrine tumors. Cancer 2001;92:1101-1107.

7 Reid T, Oronsky B, Scicinski J, Scribner CL, Knox SJ, Ning S, Peehl DM, Korn R, Stirn M, Carter CA, et al: Safety and activity of RRx-001 in patients with advanced cancer: a first-in-human, open-label, dose-escalation phase 1 study. Lancet Oncol 2015;16:1133-1142.

-8 Zhao H, Ning S, Scicinski J, Oronsky B, Knox S, Peehl DM: Abstract 3515: RRx-001: a double action systemically non-toxic epigenetic agent for cancer therapy. Cancer Res 2015;75:3515.

-9 Zhao H, Ning S, Scicinski J, Oronsky B, Knox SJ, Peehl DM: Epigenetic effects of RRx-001: a possible unifying mechanism of anticancer activity. Oncotarget 2015;6:43172-43181.

10 Knox SJ, Ning S, Peehl DM, Oronsky B, Scicinski J: RRx-001 combined with anti-PD-L1 antibody increases the complete response rate in a preclinical myeloma model. AACR-NCI-EORTC International Conference on Molecular Targets and Cancer Therapeutics, Boston, 2015, abstract C181.

-11 Carter CA, Degesys A, Oronsky B, Scicinski J, Caroen SZ, Oronsky AL, Reid T, Cabrales P, Roswarski J: Flushing out carcinoid syndrome: beneficial effect of the anticancer epigenetic agent RRx-001 in a patient with a treatment-refractory neuroendocrine tumor. Case Rep Oncol 2015;8:461-465.

12 Brzezniak C, Schmitz B, Peterson P, Degesys A, Oronsky B, Scicinski J, Caroen SZ, Carter CA: RRx-001induced tumor necrosis and immune cell infiltration in an EGFR mutation-positive NSCLC with resistance to EGFR tyrosine kinase inhibitors: a case report. Case Rep Oncol 2016;9:45-50.

13 Oronsky B, Oronsky N, Scicinski J, Fanger G, Lybeck M, Reid T: Rewriting the epigenetic code for tumor resensitization: a review. Transl Oncol 2014;7:626-631.

14 Gennatas S, Noble J, Stanway S, Gunapala R, Chowdhury R, Wotherspoon A, Benepal T, Popat S: Patterns of relapse in extrapulmonary small cell carcinoma: retrospective analysis of outcomes from two cancer centres. BMJ Open 2015;5:e006440.

-15 Eads JR, Meropol NJ: A new era for the systemic therapy of neuroendocrine tumors. Oncologist 2012;17:326-338.

16 Shih K, Arkenau HT, Infante JR: Clinical impact of checkpoint inhibitors as novel cancer therapies. Drugs 2014;74:1993-2013. 


\section{Case Reports in Oncology}

\begin{tabular}{l|l}
\hline Case Rep Oncol 2016;9:164-170 \\
\hline DOI: 10.1159/000444633 & $\begin{array}{l}\text { ○ 2016 The Author(s). Published by S. Karger AG, Basel } \\
\text { www.karger.com/cro }\end{array}$ \\
\hline
\end{tabular}

Carter et al.: Immune Reactivity and Pseudoprogression or Tumor Flare in a Serially Biopsied Neuroendocrine Patient Treated with the Epigenetic Agent RRx-001

\section{Percent Distribution NET}

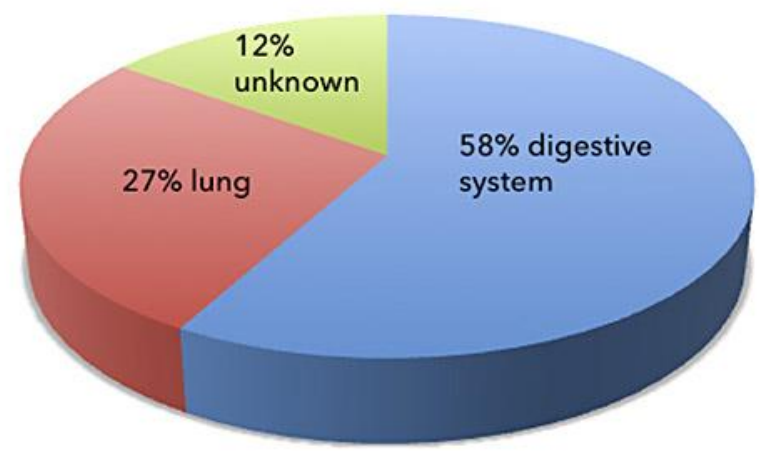

Fig. 1. The percent distribution of NETs based on anatomical location. The gastrointestinal tract, particularly the pancreas, small bowel and appendix, is the primary site of origin of NET, followed by the lungs. Up to $15 \%$ of the patients present metastases from an unknown primary site. Adapted from Yao et al. [2].
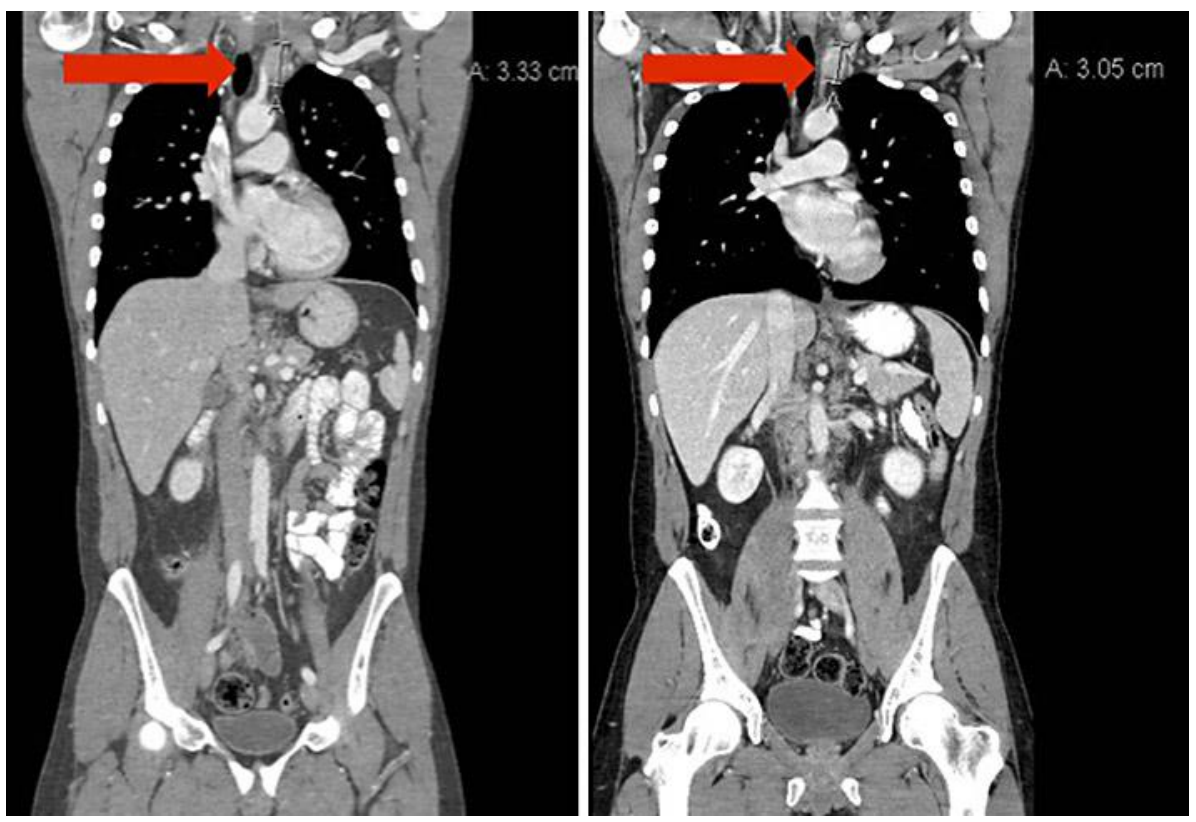

Fig. 2. CT scan pretreatment and at 4 weeks demonstrating enlargement of a supraclavicular node (red arrow). 
Carter et al.: Immune Reactivity and Pseudoprogression or Tumor Flare in a Serially Biopsied Neuroendocrine Patient Treated with the Epigenetic Agent RRx-001

\section{Supraclavicular LN}

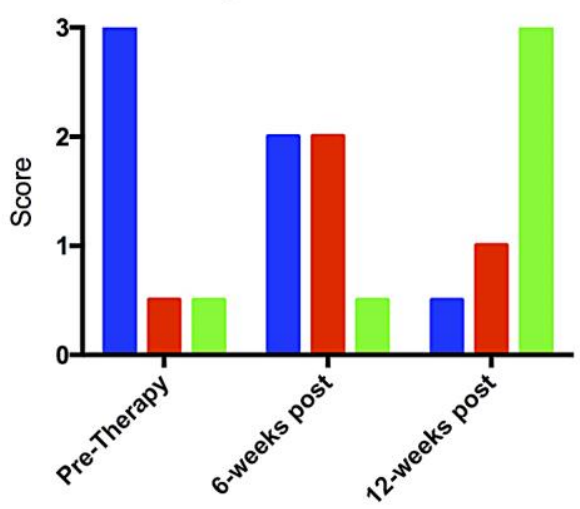

Cellularity

Necrosis

T-cells

Supraclavicular LN

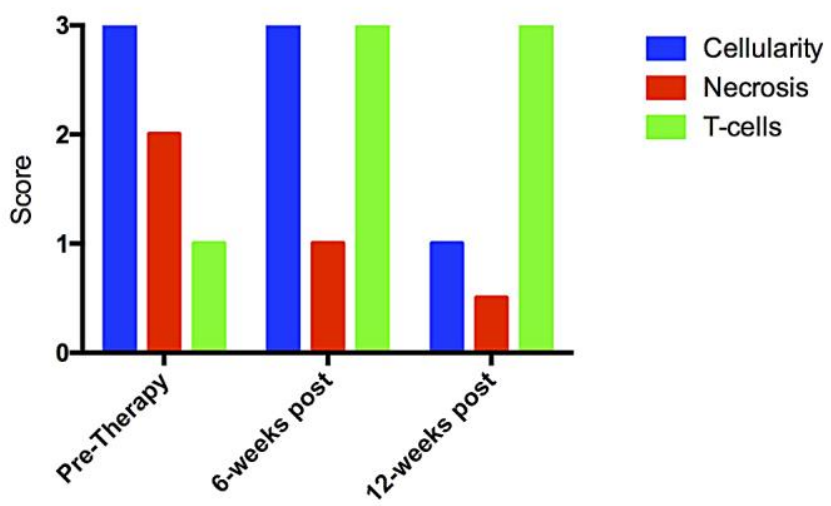

Fig. 3. Graph plotting relative cellularity, necrosis and $\mathrm{T}$ cell infiltrate per $40 \times$ high-power field (HPF) pretreatment vs. 6 and 12 weeks posttreatment using a customized scoring scale from 0 to 3 . Scoring was carried out as follows: cellularity by Ki-67 index: $1=<2 \%, 2=2-20 \%, 3=>20 \%$; necrosis: $1=$ punctuate $/$ focal, 2 = geographic, 3 = widespread. $\mathrm{T}$ cell infiltrate: scoring by number of CD3+ T-cells per $40 \times$ HPF. LN = Lymph node. 


\section{Case Reports in Oncology}
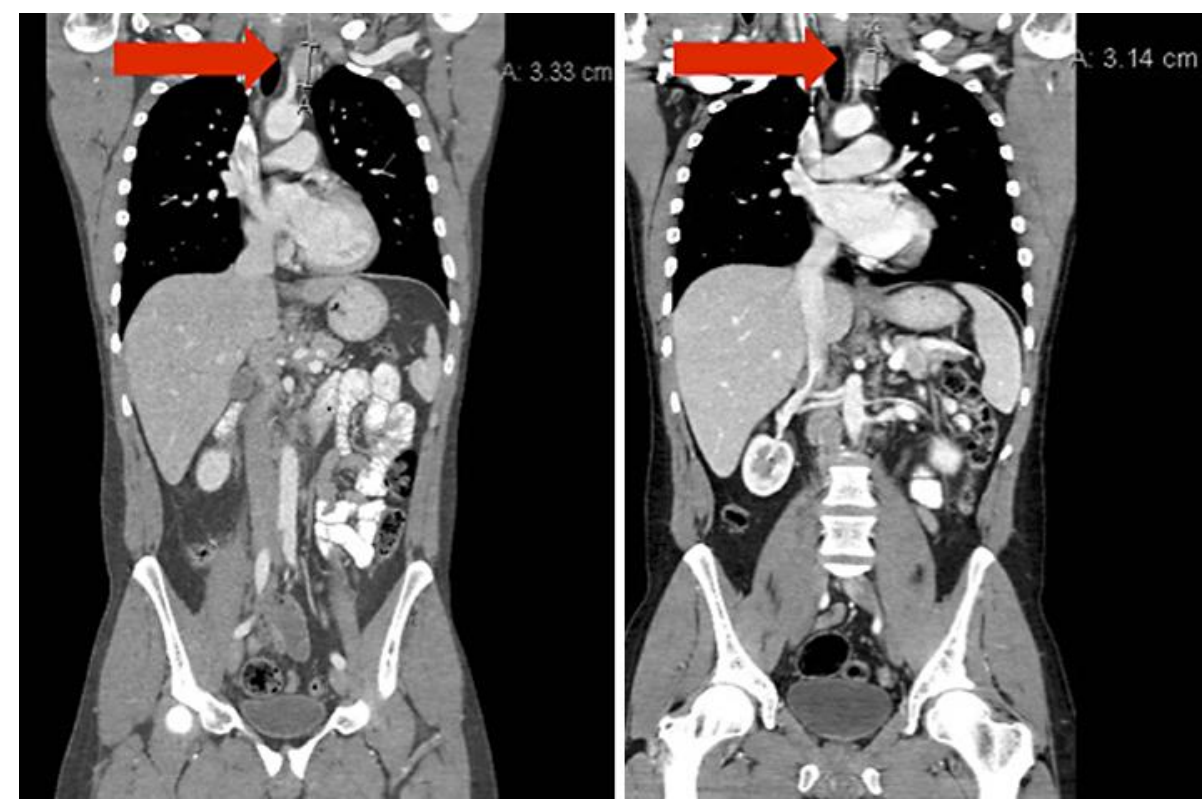

Fig. 4. CT scan at 4 weeks and at 8 weeks demonstrating shrinkage of the supraclavicular node (red arrow), indicative of pseudoprogression. 